\title{
New Method of Determining Decision Making Unit Congestion under Inter-Temporal Dependence
}

\section{Tahereh Shahsavan}

IAU: Islamic Azad University

masoud Sanei ( $\square$ masoudsanei49@yahoo.com )

Islamic Azad University

\section{Ghasem Tohidi}

IAU: Islamic Azad University

\section{Farhad Hosseinzadeh Lotfi}

IAU: Islamic Azad University

\section{Saeid Ghobadi}

IAU: Islamic Azad University

\section{Research Article}

Keywords: Data envelopment analysis (DEA), congestion, inter-temporal dependence

Posted Date: May 10th, 2021

DOI: https://doi.org/10.21203/rs.3.rs-458961/v1

License: (c) (1) This work is licensed under a Creative Commons Attribution 4.0 International License. Read Full License

Version of Record: A version of this preprint was published at Soft Computing on February 1st, 2022. See the published version at https://doi.org/10.1007/s00500-021-06566-8. 


\title{
New Method of Determining Decision Making Unit Congestion under Inter-Temporal Dependence
}

Tahereh Shahsavan ${ }^{\mathrm{a}}$, Masoud Sanei. ${ }^{\mathrm{a}, 1}$, Ghasem Tohidi. ${ }^{\mathrm{a}}$, Farhad Hosseinzadeh Lotfi. ${ }^{\mathrm{b}}$, Saeid Ghobadi $^{\mathrm{c}}$

${ }^{a}$ Department of Mathematics, Center Tehran Branch, Islamic Azad University, Tehran, Iran

${ }^{b}$ Department of Mathematics, Science and Research Branch, Islamic Azad University, Tehran, Iran

${ }^{\mathrm{c}}$ Department of Mathematics, Khomeinishahr Branch, Islamic Azad University, Isfahan, Iran

\begin{abstract}
Congestion is an important concept in data envelopment analysis (DEA). It occurs when the decrease of at least one decision making unit (DMU) input results in the increase of at least one output ineffective on other inputs or outputs. Until present, various methods have been discussed in terms of congestion determination in static DEA although no study has still been performed on congestion calculation in dynamic DEA under inter-temporal dependence. In this paper, congested input levels in multi-period production systems under inter-temporal dependence and further, the inter-temporal dependence of production periods due to the stock capital are studied. The advantage of dynamic DEA congestion method specification lies in the prevention of inappropriate resources allocation during evaluation periods. The validity of the proposed method has further been demonstrated via empirical example for better observation.
\end{abstract}

Keywords: Data envelopment analysis (DEA); congestion; inter-temporal dependence.

${ }^{1}$ Corresponding author:

E-mail address: Masoudsanei49@yahoo.com 


\title{
New Method of Determining Decision Making Unit Congestion under Inter-Temporal Dependence
}

\begin{abstract}
Congestion is an important concept in data envelopment analysis (DEA). It occurs when the decrease of at least one decision making unit (DMU) input results in the increase of at least one output ineffective on other inputs or outputs. Until present, various methods have been discussed in terms of congestion determination in static DEA although no study has still been performed on congestion calculation in dynamic DEA under inter-temporal dependence. In this paper, congested input levels in multi-period production systems under inter-temporal dependence and further, the inter-temporal dependence of production periods due to the stock capital are studied. The advantage of dynamic DEA congestion method specification lies in the prevention of inappropriate resources allocation during evaluation periods. The validity of the proposed method has further been demonstrated via empirical example for better observation.
\end{abstract}

Keywords: Data envelopment analysis (DEA); Congestion; Inter-temporal dependence.

\section{Introduction}

Data envelopment analysis (DEA) is a non-parametric method based on mathematical programming, applied to evaluate the performance of decision making units. The first DEA model was proposed by charnes et al. (1978); various other models were introduced by other researchers. In static DEA model, the time factor is not considered; if time factor is applied the DEA models can be called dynamic DEA models. During the recent decade, researchers have assessed the efficiency of DMU in dynamic production systems with inter-temporal dependence and have further reviewed the input and output levels. The inter-temporal dependence factors of assessment periods may include: stock capital, lagged output, capital output, and quasi-fixed inputs. In this survey, stock capital was used to determine inter-temporal dependence between input and output levels in multi-period production systems. According to Nemoto and Goto (2003) however, dynamic overall efficiency is obtained by considering quasi-fixed inputs. Also Sueyoshi and Sekitani (2005) determined the return to scale in dynamic DEA by presence of quasi-fixed inputs. Emrouznejad and Thanassoulis (2005) considered the stock capital as a factor of inter-temporal dependence of evaluation periods and achieved the dynamic-technical efficiency of DMU with a development model. The Emrouznejad and Thanassoulis (2005) model was enhanced by Jahanshahloo et al. (2006) and solved the problem of identifying dynamically efficient paths. This case of the inter-temporal dependence has been studied from both theoretical and practical aspects in the inverse DEA problems (Ghobadi et al. 2014, 2019; Jahanshahloo 2015), estimating units cost-efficiency (Soleimani-Chamkhorami and Ghobadi 2021), the problem of merging units (Zeinodinand Ghobadi 2020), and ranking of units ( Moonesian et al. (2020)). Nonetheless, in 2009 Kao additionally studied the inter-temporal dependence of assessment periods caused by the intermediate product or quasi-fixed inputs and discovered a mathematical relation between the overall and period efficiencies. Tone et al. (2010) introduced a dynamic non-radial model and divided the carry-over activities between two consecutive terms into four categories: desirable, undesirable, discretionary, and non-discretionary. Ghobadi et al. (2018) proposed a linear programing model to estimate of the technical efficiency of units. The use of the dynamic DEA model in industry was first performed by Fallah et al. (2014). Efficiency evaluation of the regional high-tech industry in china were performed using meta-frontier dynamic DEA by Li et al. (2017). 
Mariz et al. (2018) reviewed the articles on dynamic data envelopment analysis models from 1996 to 2016. An application of dynamic DEA to achieve the multi-period R\&D efficiency of regional systems has been identified by Chen et al. (2018). Simultaneous estimation of input-output level has been studied by Ghobadi (2020) using ERM-model under inter temporal dependence. Lin et al. (2021) determined efficiency score of each period using a multiplier dynamic DEA model based on directional distance function. Zhou et al. (2021) used uncertain dynamic DEA to obtain supplier's goal setting under sustainable conditions. Numerous other studies on dynamic DEA have also been carried till present but no research on dynamic congestion under the inter-temporal dependence of the input and output levels need yet to be conducted.

Congestion is a significant issue in economy and a futile step in the production systems to reduce output. First survey on congestion was published by Fare and Svensson (1980). Next, in 1986 by using the data envelopment analysis mode, congestion model was described by Fare et al. Congestion was later used by Brocket et al. (1998) in Chinese industrial sector. Cooper et al. (1996) introduced a model based on the slack variable for determining congestion. Cooper et al. (2002) Additionally calculated the congestion using a one-model method. Tone et al. (2004) on the other hand, provided a non-radial model for identifying the weak congestion and also, discerned the strong congestion by application of multiplier model and the upper bound of scale elasticity. Sueyoshi et al. solved the issue associated with the multiple optimal solutions in 2009; the theoretical relation between congestion and negative return to scale was further examined. Other studies on congestion were also carried, such as Wei and Yan (2004) who identified congestion and variant types of returns to scale. In 2009, the same resolved weak congestion using an outputoriented additive model. Kao (2010) however, reduced congestion by merging DMUs. Asgharian et al. (2010) measured congestion by stochastic data envelopment analysis. Mitheon et al. (2013) also studied congestion in two-stage supply chain. Fang (2015) on the other hand, calculated congestion by application of directional distance function and presence of desirable and undesirable outputs. Khoveyni et al. (2017) and Mehdiloozad et al. (2018) identified DMU congestion by present of negative data. The congestion of DMUs in fuzzy data envelopment analysis was determined by khirrollahi et al. (2017). Abrahimzade Adimi et al. (2019) identified the boundary between congested units and non-congested units by introducing a congestion hyperplane. Shabanpour et al. (2019) evaluated the sustainability of supplier using the data envelopment analysis congestion method. Mehdiloozad et al. (2020) specified the congestion using a maximal element of a non-negative polyhedral set and by solving a linear programming model. Khezri et al. (2019) obtained directional congestion in a situation where at least one input or output direction is not known but still did not study dynamic DEA congestion with inter-temporal dependence between input and output levels.

In this paper, congestion calculation method of dynamic DEA under inter-temporal dependence of input and output levels is studied. In addition, congestion amount of congested levels during assessment periods is reviewed i.e. congestion is calculated by multi-period production systems where the stock capital is a factor of the inter-temporal dependence of input and output levels. Also in this research, application of dynamic model to congested paths in accordance with Emrouznejad and Thanassoulis (2005) is further studied. By identification of congested paths, improper allocation of resources is prevented and on top, in order to prove the dependent hypothesis was put into practice in a banking sector as sample.

The remainder of the study is as follows. In section 2, Cooper's method of identifying congestion using non-radial model is presented with a reminder of dynamic model from Emrouznejad and Thanassoulis (2005). In section 3 however, proposed method to calculate the congestion in 
dynamic DEA under inter-temporal dependence between assessment periods is also studied. A practical example of the proposed model is provided in section 4 and finally in Section 5, the conclusion of the survey is presented.

\section{Preliminaries}

In this section, a congestion identification model similar to the Cooper et al. (2002) model is presented. In addition, the Emrouznejad and Thanassoulis (2005) model is also mentioned in this section.

\subsection{Identification of the congestion}

It is assumed that there are $\mathrm{n}$ DMUs i.e. $\left\{D M U_{j} \mid j=1, \ldots, n\right\}$, each DMU has $\mathrm{m}$ inputs i.e. $\left\{x_{i j} \mid i=1, \ldots, m\right\}$ and s outputs i.e. $\left\{y_{r j} \mid r=1, \ldots, s\right\}$. The congestion production possibility set under the inputs weak disposability is defined as follow:

$P P S_{\text {congestion }}=\left\{\left(\begin{array}{l}x \\ y\end{array}\right) \epsilon R^{m+s} \mid \sum_{j=1}^{n} \lambda_{j} x_{i j}=x, \sum_{j=1}^{n} \lambda_{j} y_{r j} \geq y, \sum_{j=1}^{n} \lambda_{j}=1, \lambda_{j} \geq 0\right\}$,

Where $\lambda_{j}(j=1, \ldots, n)$ is the intensity variable.

Cooper's non-radial one-model method for calculating the amount of the input congestion is as follows:

$\begin{array}{lll}\operatorname{Max} & \sum_{r=1}^{s} s_{r k}^{+}-\epsilon \sum_{i=1}^{m} s_{i k}^{c} & \\ \text { s.t } & \sum_{j=1}^{n} \lambda_{j} x_{i j}+s_{i k}^{c}=x_{i k} & i=1, \ldots, m, \\ & \sum_{j=1}^{n} \lambda_{j} y_{r j}-s_{r k}^{+}=y_{r k} & r=1, \ldots, s, \\ & \sum_{j=1}^{n} \lambda_{j}=1 & \\ & s_{i k}^{c} \geq 0 & i=1, \ldots, m, \\ & s_{r k}^{+} \geq 0 & r=1, \ldots, s, \\ & \lambda_{j} \geq 0 & j=1, \ldots, n .\end{array}$

In the model (1) $s_{r k}^{+}$and $s_{i k}^{c}$ indicate the $r^{\text {th }}$ output slack variable of $D M U_{k}$ and the $i^{\text {th }}$ congestion variable of $D M U_{k}$ respectively. Also, $\epsilon$ is a non-Archimedean small positive number. Model (1) is a two-phase process: (a) the maximum output shortage of $D M U_{k}$ i.e. $s_{r k}^{+^{*}}$ is specified by outputoriented non-radial BCC model and (b) while keeping $y_{r k}=y_{r k}+s_{r k}^{+^{*}}$, the minimum of the input surpluses of $D M U_{k}$ is specified such that $D M U_{k}$ is located in the congested production possibility set. If the optimal solution of phase 1 and phase 2 is positive, it can be concluded that an increase of input reduces output. In other word, there is congestion in $D M U_{k}$. the amount of the inputs congestion is revealed with the following theorem, quite similar to the theorem of Cooper et al. (2002).

Theorem 2.1. $D M U_{k}$ is congested if and only if in an optimal solution i.e. $\left(s_{r k}^{+^{*}}, s_{i k}^{c^{*}}\right)$ of model (1) the following condition is satisfied:

There is at least one $\mathrm{r}(\mathrm{r}=1, \ldots, \mathrm{s})$ so that $s_{r k}^{+^{*}}>0$ and at least one $\mathrm{i}(\mathrm{i}=1, \ldots, \mathrm{m})$ so that $s_{i k}^{c^{*}}>0$. 
In theorem (1) $s_{i k}^{c^{*}}$ is the amount of the congestion of $i^{t h}$ input of the $D M U_{k}$ and $s_{r k}^{+^{*}}$ is the amount of the shortfall in $r^{\text {th }}$ output due to congestion and inefficiency of the $D M U_{k}$.

\subsection{Dynamic DEA under inter-temporal dependence}

In this section, a special model of dynamic DEA under inter-temporal dependence of Emrouznejad and Thanassoulis (2005) has been reviewed. According to Emrouznejad and Thanassoulis the stock capital change is specific case of the inter-temporal dependence between input and output levels in a dynamic DEA framework. They measured the performance of $n$ DMU set within assessment of window time period $W=\{t \mid t=\tau, \ldots, \tau+T\}$. The initial and terminal time period in assessment window is indicated by $\tau, \tau+T$, respectively. Each DMU is assumed to have three types of input for every time: period-specific input, stock capital inputs, and initial-stock inputs. Moreover, each DMU produces two types of outputs: period-specific outputs and terminal-stock outputs. The set of inputs and outputs of $D M U_{j}$ is defined as follows:

Period-specific input paths: $x_{i j}^{\tau} \quad i \in I_{1}, \tau \in W$,

Stock capital input paths: $z_{i j}^{\tau} \quad i \in I_{2}, \tau \in W$,

Initial-stock inputs: $Z_{i j}^{\tau-1} \quad i \in I_{2}$,

Period-specific output paths: $y_{r j}^{\tau} r \in O, \tau \in W$,

Terminal-stock inputs as output: $Z_{i j}^{\tau+T} \quad i \in I_{2}$.

Where the set of outputs, $O=\{1, \ldots, s\}$ and the set of inputs, $I=\{1, \ldots, m\}$ are divided into two subsets: $I_{1}$ (period-inputs) and $I_{2}$ (capital-inputs), such that $I_{1}, I_{2} \subset I, I_{1} \cup I_{2}=I, I_{1} \cap I_{2}=\emptyset$. Capital input $\left(z^{t}\right)$ and terminal-stock input $\left(Z^{\tau+T}\right)$ as output are supplied by initial-stock input $\left(Z^{\tau-1}\right)$. Jahanshahloo et al. (2015) still modified by Emrouznejad and Thanassoulis (2005) model, adding the following equation.

$Z^{\tau-1}=\sum_{t=\tau}^{\tau+T} Z^{t}+Z^{\tau+T}$

Emrouznejad and Thanassoulis (2005) model of production flow is shown in figure 1.

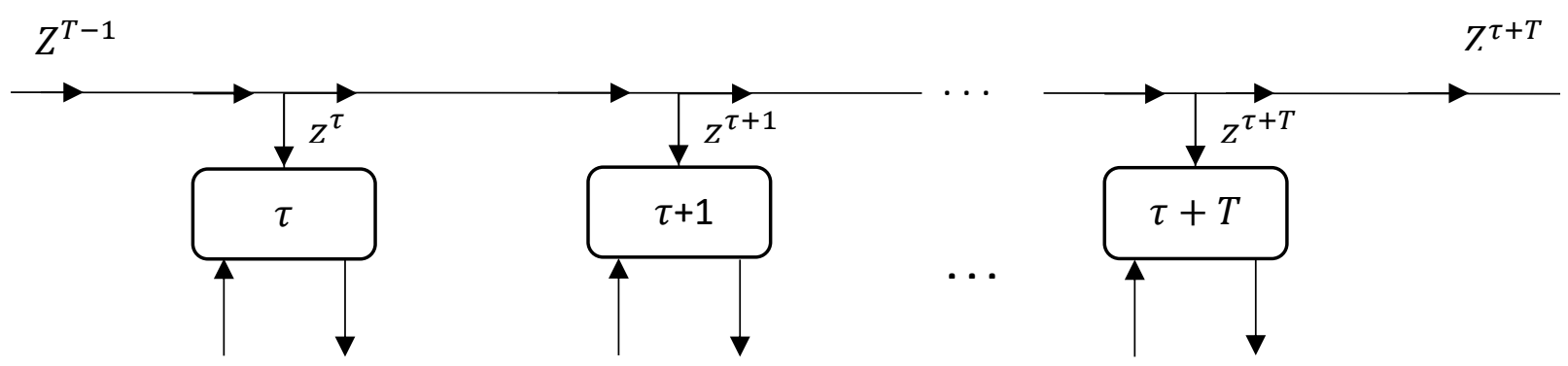




$$
x^{\tau} \quad y^{\tau} \quad x^{\tau+1} \quad y^{\tau+1} \quad x^{\tau+T} \quad y^{\tau+T}
$$

Fig. 1. Production flow in the assessment window.

They have introduced a dynamic production possibility set (PPS) as follows:

$$
P P S_{D}=\left\{\begin{array}{l|l}
\left(x^{\tau, \ldots, \tau+T}, z^{\tau, \ldots, \tau+T}, y^{\tau, \ldots, \tau+T}, Z^{\tau-1}, Z^{\tau+T}\right) & \begin{array}{l}
\sum_{j=1}^{n} \lambda_{j} x_{j}^{t} \leq x^{t}, \sum_{j=1}^{n} \lambda_{j} z_{j}^{t} \leq z^{t}, \\
\sum_{j=1}^{n} \lambda_{j} y_{j}^{t} \geq y^{t}, \sum_{j=1}^{n} \lambda_{j} Z_{j}^{\tau-1} \leq Z^{\tau-1} \\
\sum_{j=1}^{n} \lambda_{j} Z_{j}^{\tau+T} \geq Z^{\tau+T} \\
\sum_{j=1}^{n} \lambda_{j}=1, \lambda_{j} \geq 0, \forall t \in W .
\end{array}
\end{array}\right\} .
$$

A linear programing problem for estimating the dynamic relative efficiency of DMU was presented by Emrouznejad and Thanassoulis (2005). Again, this model was modified by Jahanshahloo et al. (2006). (For further details refer to Emrouznejad and Thanassoulis (2005) and Jahanshahloo et al. (2006) hypotheses).

\section{Proposed method to calculate the congestion in dynamic DEA under inter-temporal dependence}

In this section, first the dynamic congested production possibility set under inputs weak disposability is specified, next, the amount of DMU congestion in dynamic DEA is determined i.e. when the stock capital has affected inputs and outputs levels in multi period production systems.

\subsection{The dynamic congested production possibility set (Dynamic congested PPS)}

The dynamic congested production possibility set under weak disposability of inputs is defined by:

$$
P P S_{D C}=\left\{\begin{array}{l|l}
\left(x^{\tau, \ldots, \tau+T}, z^{\tau, \ldots, \tau+T}, y^{\tau, \ldots, \tau+T}, Z^{\tau-1}, Z^{\tau+T}\right) & \begin{array}{l}
\sum_{j=1}^{n} \lambda_{j} x_{j}^{t}=x^{t}, \sum_{j=1}^{n} \lambda_{j} z_{j}^{t}=z^{t}, \\
\sum_{j=1}^{n} \lambda_{j} y_{j}^{t} \geq y^{t}, \sum_{j=1}^{n} \lambda_{j} Z_{j}^{\tau-1}=Z^{\tau-1} \\
\sum_{j=1}^{n} \lambda_{j} Z_{j}^{\tau+T}=Z^{\tau+T}, \\
\sum_{j=1}^{n} \lambda_{j}=1, \lambda_{j} \geq 0, \forall t \in W .
\end{array}
\end{array}\right\}
$$

The postulates of observations, convexity, and strong disposability of period-outputs satisfy the dynamic congested production possibility set. Terminal stock as output depend on stock capital inputs. The postulate of inputs weak disposability satisfied stock capital inputs and by so doing terminal stock as output satisfied the outputs weak disposability axiom.

Since congestion is a frontier concept, model (2) is proposed to obtain an efficient unit or projection of an inefficient unit in the dynamic congested production possibility set. In other words, dynamic output-oriented model under weak disposability of inputs is presented in model (2). Unit under evaluation in model (2) is $D M U_{k}$. 


$$
\begin{array}{lll}
\operatorname{Max} & \sum_{t=\tau}^{\tau+T} \sum_{r=1}^{s} s_{r}^{+t} & \\
\text { s.t. } & \sum_{j=1}^{n} \lambda_{j} x_{i j}^{t}=x_{i k}^{t} & i \in I_{1}, t \in W, \\
& \sum_{j=1}^{n} \lambda_{j} z_{i j}^{t}=z_{i k}^{t} & i \in I_{2}, t \in W, \\
& \sum_{j=1}^{n} \lambda_{j} Z_{i j}^{\tau-1}=Z_{i k}^{\tau-1} & i \in I_{2}, \\
& \sum_{j=1}^{n} \lambda_{j} y_{i j}^{t}-s_{r}^{+t}=y_{i k}^{t} & r=1, \ldots, s, t \in W, \\
& \sum_{j=1}^{n} \lambda_{j} Z_{i j}^{\tau+T}=Z_{i k}^{\tau+T} & i \in I_{2}, \\
& \sum_{j=1}^{n} \lambda_{j}=1, & \\
& Z_{i j}^{\tau-1}=\sum_{t=\tau}^{\tau+T} z_{i j}^{t}+Z_{i j}^{\tau+T} & i \in I_{2}, j=1, \ldots, n, \\
& \lambda_{j} \geq 0 & j=1, \ldots, n, \\
& s_{r}^{+t} \geq 0 & r=1, \ldots, s, t \in W .
\end{array}
$$

Where $s_{r}^{+t}$ indicates the amount of $\mathrm{r}^{\text {th }}$ the output slack in the time period $\mathrm{t}$ and also $\lambda_{j}$ displays the amount of $j^{\text {th }}$ the intensity variable.

Here, efficient and congested units from static DEA to dynamic DEA can be defined in details.

Definition 3.1. (Dynamically efficient) Suppose $\left(s_{r}^{+t^{*}}, \lambda_{j}^{*}\right)$ is an optimal solution of model (2) then the assessment path of $D M U_{k}$ is dynamically efficient if and only if for each $\mathrm{r}(\mathrm{r}=1, \ldots, \mathrm{s})$ and for each $\mathrm{t} \quad(t=\tau, \ldots, \tau+T), \quad s_{r}^{+t^{*}}=0$, otherwise, projection of the $D M U_{k}$ i.e. $\left(x_{k}^{\tau, \ldots, \tau+T}, z_{k}^{\tau, \ldots, \tau+T}, y_{k}^{\tau, \ldots, \tau+T}+s_{k}^{(\tau, \ldots, \tau+T)^{*}}, Z_{k}^{\tau-1}, Z_{k}^{\tau+T}\right)$ is dynamically efficient.

Definition 3.2. (Congested path) The efficient assessment path $\left(x_{k}^{\tau, \ldots, \tau+T}, z_{k}^{\tau, \ldots, \tau+T}, y_{k}^{\tau, \ldots, \tau+T}, Z_{k}^{\tau-1}, Z_{k}^{\tau+T}\right)$ of $D M U_{k}$ in model (2) is called congested path when an increase (decrease) of at least one input in least one time period is associated with a decrease (increase) of at least one output in least one time period, without negative impact on other inputs and outputs.

\subsection{Determination of the amount of DMU congestion in dynamic DEA}

In this section, the amount of DMU congestion and the congested paths in dynamic DEA is determined by application of Emrouznejad and Thanassoulis (2005) model where the intertemporal dependence factor of evaluation periods is stock capital. In model (3) however, in order to calculate the congested path, first the maximum increase period outputs of $D M U_{k}$ is specified. Next, the minimum decrease of period and capital inputs is obtained such that $D M U_{k}$ is located in the dynamic congested production possibility set. In addition, the terminal-stock inputs as outputs is considered fixed.

$$
\begin{array}{lll}
\operatorname{Max} & \sum_{t=\tau}^{\tau+T} \sum_{r=1}^{s} s_{r}^{+t}-\epsilon\left(\sum_{t=\tau}^{\tau+T} \sum_{i \in I_{1}} s_{i}^{-t}+\sum_{t=\tau}^{\tau+T} \sum_{i \in I_{2}} \delta_{i}^{-t}+\sum_{i \in I_{2}} \gamma_{i}^{-}\right) \\
\text {s.t. } & \sum_{j=1}^{n} \lambda_{j} x_{i j}^{t}+s_{i}^{-t}=x_{i k}^{t} & i \in I_{1}, t \in W, \\
& \sum_{j=1}^{n} \lambda_{j} z_{i j}^{t}+\delta_{i}^{-t}=z_{i k}^{t} & i \in I_{2}, t \in W, \\
& \sum_{j=1}^{n} \lambda_{j} Z_{i j}^{\tau-1}+\gamma_{i}^{\tau-1}=Z_{i k}^{\tau-1} & i \in I_{2}, \\
& \sum_{j=1}^{n} \lambda_{j} y_{i j}^{t}-s_{r}^{+t}=y_{i k}^{t} & r=1, \ldots, s, t \in W, \\
& \sum_{j=1}^{n} \lambda_{j} Z_{i j}^{\tau+T}=Z_{i k}^{\tau+T} & i \in I_{2},
\end{array}
$$




$$
\begin{array}{ll}
\sum_{t=\tau}^{\tau+T} \delta_{i}^{-t}=\gamma_{i}^{\tau-1} & i \in I_{2}, \\
\sum_{j=1}^{n} \lambda_{j}=1, & \\
\lambda_{j} \geq 0 & j=1, \ldots, n, \\
s_{i}^{-t} \geq 0 & i \in I_{1}, t \in W, \\
\delta_{i}^{-t} \geq 0 & i \in I_{2}, t \in W, \\
\gamma_{i}^{-t} \geq 0 & i \in I_{2}, \\
s_{r}^{+t} \geq 0 & r=1, \ldots, s, t \in
\end{array}
$$

Nonetheless in the model (3) $s_{i}^{-t}, \delta_{i}^{-t}$, and $s_{r}^{+t}$ are the period-input, capital-input, and periodoutput the slack variables in the period t respectively. Also $\gamma_{i}^{\tau-1}$ is the slack variable of initialstock input. In order to, the projection of the $D M U_{k}$ satisfies in the equation $Z^{\tau-1}=$ $\sum_{t=\tau}^{\tau+T} z^{t}+Z^{\tau+T}$, the constraint $\sum_{t=\tau}^{\tau+T} \delta_{i}^{-t}=\gamma_{i}^{\tau-1}$, is applied in model (3).

Consequently, on the basis of the following theorem, the congested paths and the amount of DMU congestion at each evaluation period are identified.

Theorem 3.1. The assessment path $\left(x_{k}^{\tau, \ldots, \tau+T}, z_{k}^{\tau, \ldots, \tau+T}, y_{k}^{\tau, \ldots, \tau+T}, Z_{k}^{\tau-1}, Z_{k}^{\tau+T}\right)$ of $D M U_{k}$ is congested if and only if for an optimal solution i.e. $\left(s_{i}^{-t^{*}}, \delta_{i}^{-t^{*}}, \gamma_{i}^{(\tau-1)^{*}}, s_{r}^{+t^{*}}, \lambda_{j}^{*}\right)$ in model (3) the following condition exists:

There is at least one $\mathrm{r}(r=1, \ldots, s)$ and at least one $\mathrm{t}(t=\tau, \ldots, \tau+T)$ such that $s_{r}^{+t^{*}}>0$, and at least one of the following two cases is true:

Case 1. There is at least one $i \in I_{1}$, and at least one $\mathrm{t}$ so that $s_{i}^{-t^{*}}>0$,

Case 2. There is at least one $i \in I_{2}$, and at least one $\mathrm{t}$ so that $\delta_{i}^{-t^{*}}>0$.

Proof. Model (3) is a two-phase process. In the first phase, the maximum increase of $D M U_{k}$ period-output is obtained by dynamic output-oriented non-radial model. Now, assume that $s_{r}^{t t^{*}}$ is an optimal solution in the first phase. while keeping $y_{r k}^{t}=y_{r k}^{t}+s_{r k}^{+t^{*}}$ in the second phase, minimum decrease of period and capital inputs is determined such that $D M U_{k}$ is located in the congested production possibility set. Still, if the optimal solution in phases 1 and 2 is positive, i.e. there is at least one $r$ and at least one $t$ and that $s_{r}^{+t^{*}}>0$, and also that at least one of the two cases in 1 and 2 holds true $\left(s_{i}^{-t^{*}}>0 \vee \delta_{i}^{-t^{*}}>0\right)$, it can be conclude that an assessment path $\left(x_{i k}^{\tau, \ldots, \tau+T}-s_{i k}^{(\tau, \ldots, \tau+T)^{*}}, z_{i k}^{\tau, \ldots, \tau+T}-\delta_{i k}^{(\tau, \ldots, \tau+T)^{*}}, y_{r k}^{\tau, \ldots, \tau+T}+s_{r k}^{(\tau, \ldots, \tau+T)^{*}}, Z_{i k}^{\tau-1}-\gamma_{i}^{(\tau-1)^{*}}, Z_{i k}^{\tau+T}\right)$ is found such that, a decrease in at least one of the inputs in at least one of the time periods is associated with an increase in at least one of outputs in at least one of the time periods of $D M U_{k}$. Certainly this is to the significance that $D M U_{k}$ has congestion.

Remark 1. In optimal solution of model (3), $s_{i}^{-t^{*}} \& \delta_{i}^{-t^{*}}$ are the amount of the period $\mathrm{i}^{\text {th }}$ input congestion and the amount of the capital $\mathrm{i}^{\text {th }}$ input congestion in the time period $\mathrm{t}$, respectively.

\section{Empirical example}

In this section, the applicability of proposed method was studied via banking centers empirically. The data set is based on Ghobadi et al. (2019). Twenty Iran commercial bank branches were studied for period of three months. Each branch was provided two period-inputs, a capital input, 
and three period-outputs; period-inputs are employee score and deferred claims. Moreover, if any branch appealed for grants, financial assistance from central bank (capital stock) was provided. According to the bank rating the maximum amount of central bank grants is fixed during assessment window called initial capital $\left(Z^{\tau-1}\right)$. The initial bank capital is divided between: a) time periods in assessment window and b) remainder of initial capital called terminal stock $\left(Z^{\tau+T}\right)$, used as output for final period of assessment window. Also, for each bank correlation is always created in term of:

Initial capital $=($ sum of period capitals $)+$ terminal capital

The period outputs are loans, deposit, and profit. Data set is shown in the table 1.

Table 1: The data set of 20 bank branches in the 3-month period.

The data set in period $\mathrm{t}=1$

\begin{tabular}{|l|l|l|l|l|l|l|}
\hline Bank & $\begin{array}{l}\text { Employee } \\
\text { score }\left(x_{1}\right)\end{array}$ & $\begin{array}{l}\text { Deferred } \\
\text { claims }\left(x_{2}\right)\end{array}$ & $\begin{array}{l}\text { Capital } \\
\text { input }\left(z_{1}\right)\end{array}$ & Loans $\left(y_{1}\right)$ & Deposit $\left(y_{2}\right)$ & Profit $\left(y_{3}\right)$ \\
\hline 1 & 19.83 & 4603910 & 25415944 & 75097467 & 80023776 & 2211465 \\
\hline 2 & 7.08 & 9547 & 631223 & 25258238 & 40413775 & 767801 \\
\hline 3 & 4.01 & 136115 & 39950793 & 60530507 & 48420589 & 1770276 \\
\hline 4 & 14.92 & 1035215 & 2823106 & 65413851 & 101707340 & 3898218 \\
\hline 5 & 5.33 & 1030194 & 3536597 & 45667593 & 67411796 & 1291753 \\
\hline 6 & 12.84 & 2664633 & 56976524 & 157015854 & 163070472 & 4334957 \\
\hline 7 & 15.72 & 1086083 & 260385226 & 462186659 & 397280289 & 168494852 \\
\hline 8 & 10.94 & 225665 & 22036925 & 105618280 & 130611124 & 4072227 \\
\hline 9 & 13.08 & 7480348 & 310092 & 54863663 & 90586108 & 2335849 \\
\hline 10 & 15.97 & 3486536 & 163475721 & 274163028 & 229181190 & 5869352 \\
\hline 11 & 4.53 & 1531195 & 1978878 & 27052607 & 40188125 & 557744 \\
\hline 12 & 3.88 & 106162 & 2484718 & 32767317 & 48484615 & 1044161 \\
\hline 13 & 14.6 & 430201 & 55740403 & 164983122 & 175915348 & 667562 \\
\hline 14 & 12.19 & 288733 & 45231323 & 142754970 & 155702255 & 4650278 \\
\hline 15 & 9.93 & 79572 & 3673025 & 48940586 & 72499127 & 2145795 \\
\hline 16 & 3.2 & 23274 & 10685654 & 30547469 & 32161835 & 923161 \\
\hline 17 & 19.25 & 655170 & 45300766 & 178762561 & 209467807 & 9683107 \\
\hline 18 & 6.18 & 70840 & 63930945 & 88958994 & 67461848 & 4552123 \\
\hline 19 & 6 & 5771009 & 25973395 & 49562263 & 44092348 & 695511 \\
\hline 20 & 7.86 & 604842 & 5532201 & 40493880 & 54972684 & 1539726 \\
\hline 14 & 19 & & & & & \\
\hline
\end{tabular}

The data set in period $\mathrm{t}=2$

\begin{tabular}{|l|l|l|l|l|l|l|}
\hline Bank & $\begin{array}{l}\text { Employee } \\
\text { score }\left(x_{1}\right)\end{array}$ & $\begin{array}{l}\text { Deferred } \\
\text { claims }\left(x_{2}\right)\end{array}$ & $\begin{array}{l}\text { Capital } \\
\text { input }\left(z_{1}\right)\end{array}$ & Loans $\left(y_{1}\right)$ & Deposit $\left(y_{2}\right)$ & Profit $\left(y_{3}\right)$ \\
\hline 1 & 9.38 & 4258676 & 33423425 & 77540480 & 75205729 & 2372091 \\
\hline 2 & 5.66 & 9547 & 2635237 & 28099162 & 40501342 & 767801 \\
\hline 3 & 4.76 & 136115 & 42532282 & 63386263 & 49871113 & 1779213 \\
\hline 4 & 7.69 & 1035215 & 6186940 & 69347301 & 100617551 & 3917817 \\
\hline 5 & 3.67 & 837568 & 7640404 & 51678971 & 69103984 & 137823 \\
\hline 6 & 11 & 1217053 & 73818634 & 165665373 & 158442184 & 4786804 \\
\hline
\end{tabular}




\begin{tabular}{|l|l|l|l|l|l|l|}
\hline 7 & 11.04 & 406113 & 237525938 & 457271922 & 408482255 & 17214726 \\
\hline 8 & 7.7 & 22915 & 21522051 & 111799242 & 141070488 & 4089487 \\
\hline 9 & 10.44 & 7479093 & 3651731 & 63460385 & 96511315 & 2467889 \\
\hline 10 & 12.24 & 3674116 & 193337240 & 300159210 & 241263111 & 6667268 \\
\hline 11 & 3.22 & 1512675 & 4830066 & 28785809 & 37491612 & 559513 \\
\hline 12 & 4.07 & 106162 & 3853539 & 37246308 & 52947228 & 1059440 \\
\hline 13 & 11.19 & 430201 & 50458213 & 174059672 & 195596771 & 6683103 \\
\hline 14 & 9.09 & 288733 & 63179340 & 147933524 & 144033211 & 5174718 \\
\hline 15 & 5.14 & 79572 & 2663053 & 56425243 & 87184148 & 2518669 \\
\hline 16 & 3.37 & 23274 & 16251577 & 32096496 & 29011554 & 925370 \\
\hline 17 & 12.02 & 654770 & 36316407 & 186258838 & 234294279 & 10570787 \\
\hline 18 & 6.33 & 68785 & 61785788 & 92482607 & 72931204 & 4761568 \\
\hline 19 & 5.64 & 152093 & 29507223 & 51036143 & 43318395 & 695511 \\
\hline 20 & 4.1 & 604842 & 2316070 & 44447422 & 68159592 & 1563397 \\
\hline
\end{tabular}

The data set in period $t=3$

\begin{tabular}{|l|l|l|l|l|l|l|}
\hline Bank & $\begin{array}{l}\text { Employee } \\
\text { score }\left(x_{1}\right)\end{array}$ & $\begin{array}{l}\text { Deferred } \\
\text { claims }\left(x_{2}\right)\end{array}$ & $\begin{array}{l}\text { Capital } \\
\text { input }\left(z_{1}\right)\end{array}$ & Loans $\left(y_{1}\right)$ & Deposit $\left(y_{2}\right)$ & Profit $\left(y_{3}\right)$ \\
\hline 1 & 9.39 & 4164067 & 34302366 & 79100108 & 76524475 & 2608693 \\
\hline 2 & 5.67 & 9547 & 6014493 & 31026240 & 39083163 & 767801 \\
\hline 3 & 4.76 & 136115 & 39988455 & 64986239 & 53471773 & 1936626 \\
\hline 4 & 7.7 & 1033215 & 9851458 & 73820219 & 100647643 & 3924818 \\
\hline 5 & 3.68 & 786287 & 13105122 & 58194638 & 70522315 & 1400253 \\
\hline 6 & 11.01 & 1267053 & 70323601 & 174946921 & 174602767 & 4898347 \\
\hline 7 & 11.06 & 395522 & 229207401 & 465979022 & 426766238 & 17976626 \\
\hline 8 & 7.71 & 225915 & 17014036 & 116557642 & 156249562 & 4304301 \\
\hline 9 & 10.46 & 7477837 & 10980081 & 79367959 & 107494554 & 2469807 \\
\hline 10 & 12.25 & 3657016 & 213492432 & 308891608 & 239236387 & 7726739 \\
\hline 11 & 3.22 & 1512675 & 8979634 & 31425356 & 35479015 & 579594 \\
\hline 12 & 4.07 & 106162 & 5806457 & 40643483 & 54711936 & 1069796 \\
\hline 13 & 11.2 & 430201 & 60083361 & 175858151 & 186753718 & 6685865 \\
\hline 14 & 9.1 & 277182 & 91013826 & 153347359 & 128483906 & 5174718 \\
\hline 15 & 5.15 & 79572 & 6205102 & 60613709 & 86298673 & 2764479 \\
\hline 16 & 3.37 & 23274 & 14326858 & 33842858 & 33071151 & 966104 \\
\hline 17 & 12.04 & 654770 & 39962610 & 215702229 & 274686310 & 10576311 \\
\hline 18 & 6.33 & 68211 & 61511021 & 93642456 & 74504425 & 5066401 \\
\hline 19 & 5.65 & 148329 & 31628113 & 54119292 & 45692855 & 698963 \\
\hline 20 & 4.1 & 604842 & 6803359 & 47543624 & 63980358 & 1571893 \\
\hline Initial and terminal capitals & & & & \\
\hline Bank & Initial capital $\left(Z^{0}\right)$ & & & & \\
\hline 1 & 117244609 & & & & & \\
\hline 2 & 26566357 & & & & & \\
\hline 3 & 158665116 & & & & & \\
\hline 4 & 29209796 & & & & & \\
\hline
\end{tabular}




\begin{tabular}{|l|l|l|}
\hline 5 & 39252881 & 14970758 \\
\hline 6 & 267062245 & 65943486 \\
\hline 7 & 1037209839 & 310091274 \\
\hline 8 & 87622951 & 27049939 \\
\hline 9 & 30043956 & 15102052 \\
\hline 10 & 729364697 & 159059304 \\
\hline 11 & 34213206 & 18424628 \\
\hline 12 & 34626288 & 22481574 \\
\hline 13 & 218101708 & 51819731 \\
\hline 14 & 282355290 & 82930801 \\
\hline 15 & 27056255 & 14515075 \\
\hline 16 & 51708898 & 10444809 \\
\hline 17 & 234220827 & 112641044 \\
\hline 18 & 254370473 & 67142719 \\
\hline 19 & 134860848 & 47752117 \\
\hline 20 & 25822016 & 11170386 \\
\hline
\end{tabular}

By application of proposed model (3), the dynamic congestion of twenty branches in assessment window was studied. Results of model (3) demonstrate that $s_{i}^{-t}, \delta_{i}^{-t}$, and $s_{r}^{+t}$ for all banks except the first as being zero. Therefore, it can be concluded that bank 1 has a dynamic congested path. Still, in order to remove congested path from bank 1 to attain efficient path during evaluation period, the following results were obtained in view of table 2:

1. The amounts of 5.76, 0.97 , and 0.97 of bank 1 employees score were reduced in the first, second, and third periods, respectively.

2. The excess amounts of deferred claims in bank 1 were 3293267.40 and 3159264.23 in the first, and third periods, respectively. There were no additional deferred claims in the second period.

3. The bank 1 needed less capital stock. Therefore, the amounts of 8905429.16, 10993792.12, and 10571478.49 of bank 1 capital stock were decreased in the first, second, and third periods.

4. Shortfall of output (loans) due to congestion and inefficiency were 14226309.81, 16965193.49, and 20954224.32 in first, second, and third periods, respectively.

5. for elimination of output shortage (deposit) caused by congestion and inefficiency, the amounts of 37894332.85, 41986953.64, and 45701903.51 were added to deposits in the first, second, and third periods.

6.shortage of outputs (profits) due to congestion and inefficiency were 1799012.76, 1751931.59, and 1565536.16 in the first, second, and third periods respectively.

Consequently, to determine the amount of congestion on congested path in assessment window indicates that reducing of employee score, deferred claims, and capital stock leads to increased loan, deposit, and profit. In other word, if the first bank hires employees with lower score and reduces deferred claims and also uses less capital stock, the outputs of the bank 1 shall increase in all time periods.

Table 2: The input congestion and the output shortage due to congestion and inefficiency in the assessment window. 


\begin{tabular}{|c|c|c|c|c|c|c|}
\hline \multicolumn{7}{|c|}{ The results of the model (3) in the period $t=1$} \\
\hline $\begin{array}{l}\text { Bank } \\
\text { branches }\end{array}$ & $\begin{array}{c}\text { The input } \\
\text { congestion } \\
\left(x_{1}\right)\end{array}$ & $\begin{array}{l}\text { The input } \\
\text { congestion } \\
\left(x_{2}\right)\end{array}$ & $\begin{array}{l}\text { The input } \\
\text { congestion } \\
\left(z_{1}\right)\end{array}$ & $\begin{array}{l}\text { The output } \\
\text { shortage } \\
\left(y_{1}\right)\end{array}$ & $\begin{array}{l}\text { The output } \\
\text { shortage } \\
\left(y_{2}\right)\end{array}$ & $\begin{array}{l}\text { The output } \\
\text { shortage } \\
\left(y_{1}\right)\end{array}$ \\
\hline 1 & 5.76 & 3293267.40 & 8905429.16 & 14226309.81 & 37894332.85 & 1799012.76 \\
\hline \multicolumn{7}{|c|}{ The results of the model (3) in the period $t=2$} \\
\hline 1 & 0.97 & 0 & 10993792.12 & 16965193.49 & 41986953.64 & 1751931.59 \\
\hline \multicolumn{7}{|c|}{ The results of the model (3) in the period $t=3$} \\
\hline 1 & 0.97 & 3159264.23 & 10571478.49 & 20954224.32 & 45701903.51 & 1565536.16 \\
\hline
\end{tabular}

\section{Conclusion}

So far, no method has been proposed to identify the congestion under inter-temporal dependence. In this research, a method for identifying congestion in dynamic data envelopment analysis under inter-temporal dependence is introduced whereby the stock capital is a factor of inter-temporal dependence on the input and output levels. By application of this method, unit that has congested path is identified. In addition, the amount of the excess input and the output shortage amount of congested assessment path needed to eliminate the congested assessment path and create efficient assessment path for time period is determined. Our future research is to study dynamic DEA congestion and existence of special data such as: fuzzy, interval, integer, and etc. Therefore, to determine congestion in DEA dynamic by considering quasi-fixed inputs can be a future research.

\section{Conflict of Interest:}

Author Tahereh Shahsavan declares that he has no conflict of interest.

Author Masoud Sanei declares that he has no conflict of interest.

Author Ghasem Tohidi declares that he has no conflict of interest.

Author Farhad Hosseinzadeh Lotfi declares that he has no conflict of interest.

Author Saeid Ghobadi declares that he has no conflict of interest.

Ethical approval: This article does not contain any studies with human participants or animals performed by any of the authors.

\section{References}

[1] Asgharian, M., Khodabakhshi, M., Neralic, L., Congestion in stochastic data envelopment analysis: an input relaxation approach, International Journal of Statistics and Management System, vol. 5, no. 1, pp. 84-106, 2010.

[2] Brockett, P. L., Cooper, W. W., Shin, H. C., Wang, Y., Inefficiency and congestion in Chinese production before and after the 1978 economic reforms, Socio- Economic planning sciences, vol. 32, pp. 1-20, 1998. 
[3] Charnes, A., Cooper, W. W., Rhodes, E., Measuring the efficiency of DMUs, European Journal of Operational Research, vol. 2, pp. 429-444, 1978.

[4] Chen, K., Kou, M., Fu, X., Evaluation of multi-period regional R\&D efficiency: An application of dynamic DEA to China's regional R\&D systems, Omega, vol. 74, pp. 103-114, 2018.

[5] Cooper, W. W., Thompson, R. G., Thrall, R. M., Introduction: extensions and new developments in DEA, Annals of operations research, vol. 66, pp. 3-45, 1996.

[6] Cooper, W. W., Deng, H., Huang, Z. M., Li, S. X., One model approach to congestion in data envelopment analysis, Socio-Economic planning sciences, vol. 36, pp. 231-238, 2002.

[7] Emrouznejad, A., Thanassoulis, E., A mathematical model for dynamic efficiency using data envelopment analysis. Applied Mathematics and Computation, vol. 160, pp. 363-378, 2005.

[8] Ebrahimzadeh Adimi, M., Rostamy-Malkhalifeh, M., Hossienzadeh lotfi, F., Mehrjoo, R., Mathematical Sciences, vol. 13, pp. 43-52, 2019.

[9] Fallah-Fini, S., Triantis, K., Johnson, A.L., Reviewing the literature on non-parametric dynamic efficiency measurement: state-of-the-art, Journal of Productivity Analysis, vol. 41, no. 1, pp. 51-67, 2014.

[10] Fang, L., congestion measurement in nonparametric, European Journal of operational research, vol. 245, pp. 203-208, 2015.

[11] Fare, R., Svensson, L., Congestion of production factors, Econometrica, vol. 48, pp. 1745$1752,1980$.

[12] Fare, R., Grosskopf, S., Measuring congestion in production, Zeitschrift fur Nationaiokonomie, vol. 43, pp. 257-271, 1983.

[13] Jahanshahloo, G. R., Soleimani-damaneh, M. Reshadi, M., On the pareto (dynamically) efficient paths, International Journal of Computer Mathematics, vol. 83, pp. 629-633, 2006.

[14] Jahanshahloo, G. R., Soleimani-damaneh, M., Ghobadi, S., Inverse DEA under inter-temporal dependence using multiple-objective programming, European Journal of Operational Research, vol. 240 (2), pp. 447-456, 2015.

[15] Ghobadi, S., Jahanshahloo, G., Lotfi, F. H., \& Rostamy-Malkhalifeh, M., Dynamic inverse DEA in the presence of fuzzy data, Advances in Environmental Biology, pp. 139-152, 2014.

[16] Ghobadi, S., Jahanshahloo, G., Lotfi, F. H., \&Rostamy-Malkhalifeh, M., Efficiency measure under inter-temporal dependence, International Journal of Information Technology and Decision Making, vol. 17(02), pp. 657-675, 2018. 
[17] Ghobadi, S., A generalized DEA model for inputs (outputs) estimation under inter-temporal dependence, RAIRO-Operations Research, vol. 53 (5), pp. 1791-1805, 2019.

[18] Ghobadi, s., A dynamic DEA model for resource allocation, International journal of mathematics in operational research, vol. 17, pp. 50-77, 2020.

[19] Jahanshahloo, G. R., Soleimani-damaneh, M., Ghobadi, S., Inverse DEA under inter-temporal dependence using multiple-objective programming. European journal of operational research, vol. 240, pp. 447-456, 2015.

[20] Kao, C., Congestion measurement and elimination under the framework of data envelopment analysis, International Journal of Production Economics, vol. 123, no. 2, pp. 257-265, 2010.

[21] Kao, C., Dynamic data envelopment analysis: a relational analysis, European Journal of operational research, vol. 227, no. 2, pp. 325-330, 2013.

[22] Kheirollahi, H., Hessari, P., An input relaxation model for evaluating congestion in fuzzy DEA, Croatian operational research review, vol. no. 2, 2017.

[23] Khezri, S., Dehnokhalaji, A., Hosseinzadeh Lotfi, F., A full investigation of the directional congestion in data envelopment analysis, RAIRO-Operations Research, doi:10.1051/ro/2019092, 2019.

[24] khoveyni, M., Eslami, R., khodabakhshi, M., Jahanshahloo, G. R., Hosseinzadeh Lotfi, F., Recognizing strong and weak congestion slack based in data envelopment analysis, Computers industrial engineering, vol. 64, pp. 731-738, 2013.

[25] khoveyni, M., Eslami, R., Yang. G., Negative data in DEA: Recognizing congestion and specifying the least and the most congested decision making units. Computers \& operations research vol. 79, pp. 39-48, 2017.

[26] Li, L.B., Liu, B.L., Liu, W.L., Chiu, Y.H., Efficiency evaluation of the regional high-tech industry in China: A new framework based on meta-frontier dynamic DEA analysis, Socioeconomic planning sciences, vol. 60, pp. 24-33, 2017.

[27] Lin, R., Liu, Q., Multiplier dynamic data envelopment analysis based on directional distance function: An application to mutual funds, European journal of operational research, 2021.

[28] Mariz, F.B.A.R., Almeida, M.R., Aloise, A review of dynamic data envelopment analysis: State of the art and applications, International transactions in operational research, vol. 25, pp. 469-505, 2018.

[29] Mehdiloozad, M., Zhu, J., Sahoo, B.K., Identification of congestion in data envelopment analysis under the occurrence of multiple projection: A reliable method capable of dealing with negative data, European journal of operational research, vol. 265, pp. 644-654, 2018. 
[30] Mehdiloozad, M., Sahoo, B.K., Zhu, J., Identification of congestion in DEA, Data science and productivity analytics, vol. 290, pp. 83-119, 2020.

[31] Mithun, J. sharma, Song Jin, Yu., Multi-stage data envelopment analysis congestion model, Operational Research, vol. 13, pp.399-413, 2013.

[32] Moonesian, V., Jahangiri, S., \& Ghobadi, S., Efficiency and super-efficiency under intertemporal dependence, RAIRO-Operations Research, vol. 54 (5), pp. 1385-1400, 2020.

[33] Nemoto, J., Goto, M., Measurement of dynamic efficiency in production: an application of data envelopment analysis to Japanese electric utilities, Journal of Productivity analysis, vol. 19, no. 2-3, pp.191-210, 2003.

[34] Shabanpour, H., Fathi, A., Yousefi, S., Faripoor Saen, R., Ranking sustainable suppliers using congestion approach of data envelopment analysis, Journal of cleaner production, vol. 240, pp. 118-190, 2019.

[35] Soleimani-Chamkhorami, Kh. and Ghobadi, S., Cost-efficiency under inter-temporal dependence, Ann Oper Res, https://doi.org/10.1007/s10479-021-03989-2, 2021.

[36] Sueyoshi, T., Sekitani, K., Returns to scale in dynamic DEA, European Journal of Operational Research, vol. 161, no. 2, pp. 536-544, 2005.

[37] Sueyoshi, T., Sekitani, K., DEA congestion and return to scale under an occurrence of multiple optimal projections, European journal of operational research, vol. 194, pp. 592-607, 2009.

[38] Tone, K., Sahoo, B. K., Degree of scale economic and congestion: A unified DEA approach, European journal of operational research, vol. 64, pp. 731-738, 2004.

[39] Tone, K., tsutsui, M., Dynamic DEA: A slack-bused measure approach, Omega, vol. 38, pp. 145-156, 2010.

[40] Wei, Q. L., Yan, H., Congestion and return to scale in data envelopment analysis, European journal of operational research, vol. 153, pp. 641-660, 2004.

[41] Wei, Q. L., Yan, H., Weak congestion in output additive data envelopment analysis, Socioeconomic planning sciences, vol. 43, pp. 40-54, 2009.

[42] Zeinodin, E. and Ghobadi, S., (2020). Merging decision-making units under inter-temporal dependence, IMA Journal of Management Mathematics, vol. 31(2), pp. 139-166, 2020.

[43] Zhou, X., Li, L., W, H., Wen, H., Tian, X., Wang, S., Lev, B., Supplier's goal setting considering sustainability: An uncertain dynamic data envelopment analysis based on benchmarking model, Information Sciences, vol. 545, pp. 44-64, 2021. 
Figures

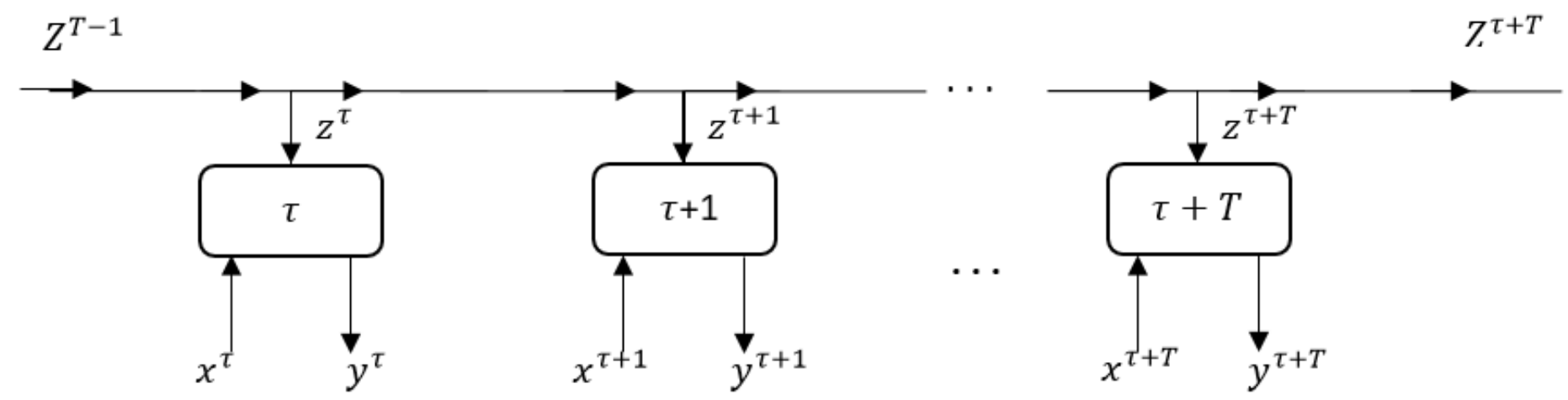

Figure 1

Production flow in the assessment window. 